\title{
Organización y proceso legislativo en el presidencialismo brasileño ${ }^{1}$
}

\author{
FABIANO SANTOS
}

\section{Resumen}

Gran parte de la literatura comparada sobre las instituciones políticas trata los sistemas presidencialistas y parlamentaristas como casos opuestos, especialmente en lo que atañe a las relaciones entre Ejecutivo y Legislativo y al comportamiento de los partidos en el Congreso. No obstante, un creciente número de trabajos han mostrado que las experiencias presidencialistas en América del Sur tienden a apoyarse cada vez más en gobiernos de coalición vistos como formas de dar estabilidad al proceso político, algo que es común a los países parlamentaristas de Europa. Este artículo tiene como objetivo analizar las consecuencias de este modelo -el llamado presidencialismo de coalición- para el funcionamiento del Congreso en el Brasil contemporáneo.

\begin{abstract}
The comparative literature on political institutions usually treats parliamentary and presidential systems as polar cases, regarding, specifically, executive legislative relationship and the behavior of political parties inside legislatures. More recently, however, as an expanding body of analysis is trying to demonstrate, South America's presidential experiences have been, in a growing fashion, making use of coalition governments as means to stabilize the political process -something rather common in the European parliamentary context. The chapter analyses the consequences of this model -the so called coalition presidentialism.
\end{abstract}

Palabras clave: Congreso - Presidencialismo de coalición - Política brasilera - Partidos Comisiones parlamentarias.

\section{Introducción ${ }^{2}$}

¿Cuál es la gran diferencia entre los sistemas presidencialista y parlamentarista de gobierno? Por de pronto conviene señalar aquello que no los distingue: estudios recientes y rigurosos sobre el tema, así como la atenta observación de la histo-

1 Traducción: TPRO, Traductores profesionales Pontificia Universidad Católica.

2 Parte de esta introducción fue publicada en la revista Foco: Economia e Negócios, No. 28, año 2, págs. 20

a 22, con el título: "Reforma Política: ¿Revolución o Superstición?”. 
ria reciente de los países democráticos, comprueban que no existen ventajas de uno sobre el otro en cuanto a los requisitos de transparencia y honestidad. Además, también es cierto que la supuesta superioridad del parlamentarismo en lo concerniente a la estabilidad del régimen fue cuestionada vigorosamente por los análisis del cientista político José Antonio Cheibub, de la Universidad de Yale ${ }^{3}$. La aparente inestabilidad de los regímenes presidenciales no pasa de una correlación espuria; de una ilusión alimentada por el hecho de que la mayoría de los países con sistemas presidencialistas son miembros del continente sudamericano. En términos generales se trata de naciones que han sido víctimas de dictaduras militares, esto es, naciones herederas de tales regímenes, que han optado por sistemas parlamentaristas o presidencialistas, pero con propensión a enfrentar crisis y retrocesos en su trayectoria de redemocratización.

Vale la pena explorar entonces aquello que, aun cuando aparece como una diferencia, no distingue propiamente a los dos sistemas en su esencia. Se dice que los sistemas parlamentarios garantizan el surgimiento de gobiernos mayoritarios, mientras que los presidenciales permitirian la formación de gobiernos minoritarios. Nada más lejos de la realidad -aproximadamente un 40\% de los gobiernos formados en los países parlamentaristas de la Europa occidental de posguerra no estaban compuestos por partidos que controlaban la mayoría de los escaños en el Legislativo- ${ }^{4}$. En una palabra, la incidencia de gobiernos de minoría es tan común en el parlamentarismo como en el presidencialismo. Se argumenta además, que los sistemas presidenciales no generan incentivos para la formación de gobiernos de coalición, lo que, una vez más, está lejos de corresponder a la realidad. Solamente en nuestro continente, desde la última ola de redemocratización, el patrón institucional por excelencia en América del Sur es el presidencialismo de coalición. Dicho patrón constituye una rica experiencia donde pueden observarse ejemplos de sólida estabilidad, como la Concertación de Partidos por la Democracia en Chile, junto con otros más bien fugaces y turbulentos, como fue en la Argentina el caso inédito del gobierno de coalición entre los radicales y el FREPASO ${ }^{5}$.

¿Cómo es posible la formación de gobiernos de minoría en sistemas parlamentaristas si se requiere la confianza de la mayoría del parlamento para la sustentación del gobierno? La explicación es simple: tener la confianza del parlamento significa que, básicamente, debe existir una mayoría partidaria que, al menos, tolere al gobierno. Ahora bien, tolerar un gobierno no es lo mismo que participar del mismo. A menudo los gobiernos se constituyen sin que formen parte del gabinete los partidos que, a través de la suma de sus bancadas, permiten alcanzar la mayoría de los escaños. Es ésta una práctica común en Escandinavia y en algunas ocasiones ha estado presente en algunos países de

\footnotetext{
El argumento se encuentra en Cheibub (2005).

El trabajo de referencia es el de Strom (1990).

Ver al respecto Anastasia, Melo e Santos (2004).
} 
Europa, como Francia y España. En cambio, cuando existe una oposición que no tolera al gobierno, eventos como la aprobación de un voto de desconfianza o la derrota del gobierno en algún punto importante de su agenda, equivalen a la pérdida de confianza en el gabinete. Esto último fuerza la convocatoria de nuevas elecciones. Es aquí, en consecuencia, donde reside la diferencia fundamental entre uno y otro sistema.

Cuando en un sistema parlamentario la mayoría legislativa está formada por partidos que hacen oposición, el parlamento puede votar una moción de desconfianza y se pueden convocar nuevas elecciones. Dicha posibilidad no existe en el sistema presidencial; en otras palabras, el gobierno puede sobrevivir no obstante enfrentar una oposición mayoritaria en el Legislativo. Ésta fue la experiencia predominante en los EE.UU. de la posguerra, con los llamados "gobiernos divididos". Del punto de vista de la conducción del proceso político y de la negociación de la agenda, los gobiernos divididos están ciertamente marcados por idas y venidas, negociaciones y, a veces, conflictos abiertos. Sin embargo, ello en nada autoriza la conclusión según la cual las oportunidades de estabilización del proceso democrático, de éxito económico de los gobiernos y de la mayor o menor capacidad de aprobar agendas, sean superiores en el parlamentarismo. Una vez más, todos los fenómenos que hacen al proceso gubernamental más lento y negociado como, por ejemplo, gobiernos de minoría, de coalición, o ambos, acontecen con la misma frecuencia en uno y otro sistema. Aquello que los diferencia es la competencia del Ejecutivo para disolver el parlamento cuando le parece de conveniencia política, ante la expectativa de aumentar su poder de negociación en el Legislativo, o la prerrogativa de este último de derribar los mandatarios del Ejecutivo, en las ocasiones en que la mayoría parlamentaria decide no tolerar la situación. En el presidencialismo, guardados los casos extremos de mala conducta, la única forma de interrupción de los mandatos parlamentarios y del jefe del Ejecutivo es a través del tradicional voto popular.

\section{Definición y práctica del presidencialismo de coalición en América del Sur}

¿Qué es entonces el presidencialismo de coalición? El término, que aparece en 1988 en un artículo clásico de Sérgio Abranches ${ }^{6}$, describe el patrón institucional típico de América del Sur: el Presidente construye una base de apoyo concediendo puestos ministeriales a miembros de los partidos con representación en el Congreso y ellos, a cambio, proporcionan los votos necesarios para aprobar su agenda en el Legislativo.

En realidad, la práctica del presidencialismo de coalición está bastante difundida en América del Sur. Evidencias recogidas y analizadas por Anastasia,

$6 \quad$ Ver Abranches, (1988). 
Melo y Santos (2004) revelan que, durante la década de los 90, sólo Argentina, con excepción del período de De La Rúa, no montó gobiernos de este tipo. Por otro lado, Bolivia, Brasil y Chile, sólo han conocido gobiernos con apoyo multipartidario en el Legislativo. Colombia y Uruguay también pueden ser contabilizados como países con práctica predominante de gabinetes de coalición. La incidencia de gobiernos minoritarios no es despreciable: nada menos que 42 gabinetes contaron con partidos cuyo número de escaños quedó bajo el 50\% en la Cámara Baja. De ellos, 19 fueron gabinetes de un solo partido (además de Argentina, con la participación de Colombia, Ecuador, Perú y Uruguay). Ecuador y Venezuela fueron siempre gobernados por Presidentes con apoyo minoritario en el parlamento.

Algunos países como Brasil, Bolivia, Chile, Colombia y Uruguay, practican en forma bastante consolidada la política de montaje de gobiernos mayoritarios o súper mayoritarios de coalición. Bajo este aspecto, las experiencias son desiguales: en tanto Brasil navega, preferentemente, entre coaliciones con mayorías amplias y unos pocos experimentos minoritarios (el caso aislado del gobierno de Collor), los Presidentes chilenos no montaron gobiernos minoritarios, oscilando entre la mayoría estricta y las mayorías amplias, siendo esta experiencia también rara en Bolivia. Por otro lado, en Colombia predomina el formato casi consensual y en Uruguay la práctica está bien distribuida entre los diversos formatos. Igualmente, los autores notaron que las condiciones estructurales para una relación conflictiva entre Presidente y Asamblea están dadas en pocos casos. Específicamente, Ecuador y Perú, en los cuales verificamos Presidentes con escaso apoyo en el Legislativo, aunque dotados de considerables poderes de agenda ${ }^{7}$ como, por ejemplo, el poder de decreto. En menor medida, algo semejante ocurrió en Brasil entre 1991 y 1992, período durante el cual el país fue gobernado, de manera claramente no partidaria, lo que contribuyó de forma decisiva a la acusación contra el Presidente Collor.

El objetivo de las secciones siguientes es el de caracterizar la actividad del Legislativo en el presidencialismo brasileño. Veremos que se trata de una Cámara básicamente transformadora, que en su comportamiento combina elementos distributivos y partidarios. Además, se perciben deficiencias en su capacidad informativa y dificultades para la adopción de una postura más pro-activa (sección 3). El examen de los datos e informaciones sobre la organización interna del Congreso, los poderes legislativos del Ejecutivo, la producción legislativa y el comportamiento partidario revela, por otro lado, que tales dificultades emanan de la propia naturaleza del funcionamiento del Congreso, en el contexto del presidencialismo de coalición (secciones 4 a 8). La conclusión se dedica a algunos comentarios de cuño normativo, con énfasis en el problema informativo y en la capacidad pro-activa del Legislativo.

El "poder de agenda" puede ser descrito como la "definición de los temas substantivos a ser apreciados y la determinación de los pasos y de la secuencia de procedimientos a seguir a lo largo del proceso decisorio", en Figueiredo y Limongi (1999), p. 69. 


\section{El Legislativo brasileño y los estudios legislativos}

En el área de los estudios legislativos, existen dos tradiciones. La primera, de inspiración estructural-funcionalista, procura detectar el papel, o papeles, que cumple el parlamento en un país determinado. La segunda, desarrollada a partir del abordaje neo-institucional, verifica los objetivos de carrera de los parlamentarios, así como las reglas bajo las cuales interactúan con los colegas y demás actores políticos, para luego explicar fenómenos relevantes concernientes a la vida parlamentaria, como disciplina partidaria, producción legislativa, mayor o menor predominancia del Ejecutivo, etc.

De acuerdo con el enfoque funcional, un parlamento puede ser activo, reactivo o "timbrador". . Un Legislativo activo es aquel que posee la iniciativa del proceso decisorio. Además de predominante en cuanto al origen de los proyectos aprobados, es también un actor fundamental en la implementación de los programas gubernamentales y de asignación de recursos. Una elevada complejidad interna, que se expresa en la amplia división del trabajo legislativo en comisiones técnicas, permanentes y altamente especializadas, es la marca de este tipo de parlamento. Igualmente, es común observar el predominio de carreras legislativas exclusivas; vale decir que la meta principal de la ambición de los políticos es la conquista de cargos en la jerarquía interna del Legislativo, como la presidencia de comisiones importantes, el liderazgo de bancada o puestos en la mesa directiva.

Un Legislativo reactivo es aquel que delega la iniciativa de las proposiciones legales más importantes al Ejecutivo. La definición de la agenda, así como las prioridades en lo relativo al orden de apreciación de los proyectos, es transferida al gobierno y negociada, posteriormente, con los parlamentarios que lideran el partido o coalición legislativa mayoritaria. En general, la actividad fiscalizadora de estos parlamentos está bastante difundida. No obstante, la complejidad interna no está tan desarrollada, lo que hace al parlamento hasta cierto punto dependiente de las informaciones procesadas por agentes situados fuera del ámbito legislativo, como la burocracia del Ejecutivo, el Poder Judicial o grupos de interés. Por otra parte, los políticos no otorgan prioridad a la carrera en el Legislativo prefiriendo, en la medida de lo posible, concurrir a través del voto o nominación, a puestos en el gobierno a nivel nacional o local.

Un Legislativo "timbrador" es aquel que funciona enteramente a remolque del gobierno. Los asuntos que tramitan en el Legislativo lo hacen de manera casi totalmente "pro-forma", es decir, a los órganos internos del parlamento les corresponde sólo rematar el proyecto en sus aspectos técnicos. Una vez definida una coalición legislativa mayoritaria, todo el poder decisorio y de asignación es delegado en el gobierno, que marca la pauta de los trabajos legislativos. Acontece una fusión entre los poderes legislativo y ejecutivo, cabiendo al parlamento, como

8 Ver, en esta línea de análisis, los trabajos clásicos de Polsby (1968); Packenham (1970); Blondel (1973); Loewenberg y Patterson (1979); Mezey (1985). 
institución distinta del gobierno, socializar a los parlamentarios en la vida pública y suministrar cuadros para los ministerios y secretarías de gobierno. En estos casos, la carrera de un legislador está dedicada al parlamento hasta el momento en que consigue la nominación para un ministerio, lo cual es la verdadera meta de su ambición política.

El Legislativo brasileño es reactivo. En un trabajo reciente, Amorim Neto y Santos (2002) observaron que, en un universo de más de dos mil leyes aprobadas entre 1985 y 1999, sólo 336 fueron de iniciativa parlamentaria. Además, se constató que aun cuando esas leyes eran relevantes para ciertos grupos y sectores de la sociedad, aquellas no afectaban el status quo económico y social del país, tratándose más bien de intervenciones tópicas en cuestiones concernientes a la vida del ciudadano común. Igualmente, el proceso presupuestario es controlado por el Ejecutivo y organizado para favorecer las prioridades establecidas por la coalición de partidos que dominan el gobierno, siendo la intervención de los parlamentarios apenas marginal (Figueiredo y Limongi, 2002). Si bien la complejidad interna es ahora creciente, como lo comprueba la reciente alza del número de comisiones técnicas de la Cámara de 16 a 20, es aún insuficiente para hacer frente a la inmensa capacidad de producir informaciones del Ejecutivo. Finalmente, en relación con las carreras de los legisladores, varios estudios muestran que éstas se caracterizan por el perfil "zigzag", frecuentemente con puestos electivos del Ejecutivo a nivel local como prioridad (Samuels, 2003; Santos, 2003b).

Pasemos ahora al abordaje neo-institucional aplicado al estudio del Legislativo. En esa área, los estudios - predominantemente volcados al Congreso norteamericano-, se subdividen en dos grandes grupos: existen quienes no ven relevancia en la acción de los partidos y aquéllos que consideran a los partidos como el actor clave en la organización y el proceso decisorio del Congreso.

La corriente que no considera los partidos como institución relevante se desdobla en dos sub-corrientes: la distributiva y la informativa. La primera postula que la organización del Congreso sirve a los intereses de reproducción electoral de sus miembros ${ }^{9}$. Dado que la conquista del voto es función de la capacidad del representante de atender los intereses radicados en el distrito electoral por el cual se eligió, éste procurará especializarse en temas de políticas públicas de gran impacto en ese distrito. Conviene recordar que los demás representantes enfrentan el mismo problema, lo que los lleva a desarrollar instituciones internas que permitan a los diputados adquirir "expertise" en las políticas públicas pertinentes y distribuir beneficios concentrados en los electores de su distrito. El sistema de comisiones especializadas, dotadas de amplios poderes de agenda, la regla de la antigüedad como mecanismo de acceso a posiciones de jerarquía en las mismas y los instrumentos reglamentarios que protegen los proyectos aprobados en las comisiones de modificaciones en el plenario, serían los mecanismos mediante

9 Los principales trabajos en esta línea son Mayhew (1974); Ferejohn (1974); Fiorina (1977); Shepsle (1979); Weingast y Marshall (1983); Cain, Ferejohn y Fiorina (1987). 
los cuales el proceso decisorio atendería el esfuerzo de los representantes para distribuir sinecuras localizadas, que adquieran visibilidad para los electores. El origen de este esfuerzo remonta a la necesidad de reproducción electoral del congresista.

Donde la sub-corriente distributiva observa particularismo, la informativa ve eficiencia colectiva ${ }^{10}$. La organización del Congreso en torno a comisiones altamente especializadas constituiría un medio de atender las demandas de los congresistas por "expertise"-demanda que resulta de la tentativa de reducción de la incertidumbre que necesariamente circunda el trabajo de formulación e implementación de políticas públicas-. En realidad, tanto la regla de la antigüedad como las reglas de restricción de enmiendas a las proposiciones enviadas al plenario por las comisiones constituirían incentivos al desarrollo de las propias comisiones. Los riesgos de particularismo inherentes a un proceso decisorio compartimentado en pequeños núcleos decisorios, se verían reducidos en la medida en que las diversas tendencias de opinión existentes en el plenario, es decir, su heterogeneidad, tuvieran correspondencia en la composición de las propias comisiones.

La corriente partidaria disiente frontalmente de la asertiva, presente en el enfoque anterior, de acuerdo con la cual los partidos no serían instituciones relevantes de organización y decisión congresa ${ }^{11}$. Al contrario, según los defensores de esta corriente, las instituciones del Legislativo expresan los dilemas de acción colectiva y conflictos internos del partido o de la coalición mayoritaria. Los partidos cumplirían dos importantes funciones: servirían como vehículo para la toma de decisión del elector y como mecanismo de coordinación del comportamiento de los parlamentarios, una vez elegidos. Vale decir, los políticos extraen beneficios de la existencia de los partidos porque éstos facilitan tanto su actuación como candidatos, al señalar su posicionamiento en cuestiones de interés público, como su actuación como parlamentarios, al guiar sus decisiones en cuanto a las materias que llegan a votarse en el plenario. No obstante, el interés que subsidia la emergencia y la fuerza de los partidos es un interés de carácter colectivo. Esto es, los parlamentarios también son elegidos en consideración de los esfuerzos desplegados por cada uno de ellos para atender las demandas de sus electores. Entonces, el dilema colectivo de los políticos frente a los partidos, surge en el momento en que los primeros comprometen la imagen del partido, ya sea por la falta de atención sobre aquellos temas y políticas que identifican colectivamente al partido, o por el énfasis puesto en asuntos de alcance meramente local.

La solución clásica para los problemas de acción colectiva es delegar a un individuo o grupo de individuos la tarea de coordinar y canalizar los esfuerzos individuales hacia el bien público. Esto es, se trata de dotar a este grupo de indivi-

$10 \quad$ Ver Gilligan y Krehbiel (1987); Krehbiel (1991); Brady y Volden (1998).

11 En esa tradición, los trabajos más importantes son Kiewiet y McCubbins (1991); Rohde (1991); Cox y MacCubbins (1993); Sinclair (1995). 
duos de poder y concederle incentivos para que asuma la obligación de organizar el comportamiento individual y realizar el interés colectivo. En la vida parlamentaria y de los partidos, estos agentes reciben el nombre de liderazgos partidarios. El papel de los liderazgos partidarios no se limita, exclusivamente, a disciplinar la conducta de la bancada. Su función, más bien, estaría dirigida a impedir, por una parte, que la acción individual perjudique excesivamente la imagen colectiva de la agremiación, y, por otra, que los conflictos de interés y de opinión al interior de la bancada conduzcan a una situación de mezquindad electoral y política. En una palabra, la función del liderazgo partidario es la de compatibilizar los intereses individuales y colectivos de una misma coalición de congresistas.

La literatura reciente sobre el Congreso brasileño ha verificado la coexistencia de elementos distributivos y partidarios en el comportamiento legislativo de nuestros parlamentarios ${ }^{12}$. Indicadores como las encuestas de opinión, la producción legal, el proceso presupuestario y la disciplina partidaria revelan, al menos, dos puntos fundamentales. Primero, que existe un amplio consenso sobre la importancia de que el parlamentario erija una reputación personal ante sus electores. O sea, en Brasil, la tarea de la representación política está fuertemente anclada en la figura individual del político. No obstante, el espacio de actuación individual del parlamentario es mucho más reducido en el Congreso. Esto es, la actividad legislativa, en lo relativo a su organización y al proceso de decisión, se encuentra centralizada en el liderazgo de los partidos y, en particular, en aquellos partidos que son aliados del gobierno. Segundo, y lo que es más relevante para los fines de esta discusión, existe amplio consenso de que el Congreso brasileño carece, en su forma de actuar, de las reglas y procedimientos que incentiven el desarrollo de "expertise" y capacitación de los parlamentarios para la formulación e implementación de políticas públicas. En otros términos, le falta aún al Congreso desarrollar mecanismos informativos.

En las próximas secciones, la descripción del Congreso brasileño como institución reactiva en la cual están mezclados elementos partidarios y distributivos en su modus operandi obtendrá un respaldo empírico. En primer lugar, veremos que el montaje de coaliciones mediante la distribución de carteras ministeriales y de recursos presupuestarios es de fundamental importancia para la actividad del parlamento, de acuerdo o no con las preferencias del Ejecutivo. Además, se mostrará que el comportamiento de la coalición a favor del Ejecutivo es tanto más eficiente cuanto que el acuerdo de distribución de recursos políticos se sustenta sobre bases partidarias. Veremos también que, a pesar de que el Presidente brasileño sea institucionalmente fuerte, cada vez que pretendió ejercer sus prerrogativas a despecho de las tendencias mayoritarias presentes en el Legislativo, terminó fracasando en su intento.

12 Ver Figueiredo y Limongi (1999); Pereira y Mueller (2000); Carvalho (2003); Amorim Neto y Santos (2003). 


\section{Coaliciones parlamentarias y el montaje de ministerios en el presidencialismo brasileño}

Se puede demostrar que, en el caso brasileño, la caracterización del Congreso como básicamente transformador, asentado en principios distributivos y partidarios, emana del empeño de los Presidentes en formar ministerios tomando en cuenta tanto la fuerza y el peso relativo de los partidos en el parlamento (Abranches, 1988; Meneguello, 1998; Amorim Neto, 2000), como los poderes de agenda previstos constitucionalmente y los poderes reglamentarios a disposición de los líderes partidarios (Pessanha, 1997; Figueiredo y Limongi, 1999; Santos, 2003a). Este último tópico, así como sus impactos en términos del proceso decisorio, serán tratados en las secciones 5, 6, 7 y 8 . El primer tópico, vale decir la fuerza y peso de los partidos en el parlamento, es objeto de la presente sección -y, de inmediato, conviene recordar que, aun cuando los Presidentes no disponen de un poder de amenaza de disolución del gabinete similar al del parlamentarismo, sí pueden promover cambios ministeriales con el fin de recomponer sus bases de apoyo ${ }^{13}$.

El Cuadro 1 presenta datos sobre las coaliciones formadas entre 1985 y 2003. Permite observar el empeño de la mayoría de los gobiernos en constituir gabinetes con una fuerza parlamentaria suficiente para la aprobación futura de sus agendas - un hecho que se puede percibir en el porcentaje total de escaños controlados (nominal) por los partidos pertenecientes a la coalición gubernamental-. Esos porcentajes son más significativos en el Senado; para hacerse una idea, en las formaciones ministeriales de inicio del mandato, las coaliciones gubernamentales en los gobiernos de Sarney, Collor y FHC, tenían el control de cerca del 81,7\%, $58,1 \%$ y $68,6 \%$ de los escaños, respectivamente.

Incluso el gobierno de Collor, que trató de apartarse de esa estrategia con su postura antipartidaria, se vio luego obligado a rendirse a la misma, cuestión que pudo observarse en su tentativa final de formar un gabinete más incluyente. Tanto el gobierno de FHC como el gobierno de Lula se empeñaron en equilibrar la distribución de ministerios en función del peso de los partidos en la coalición, aunque el tamaño de la bancada parlamentaria de apoyo montada por FHC fuese bastante superior. A pesar de detentar el 49,5\% de los escaños en la Cámara, el inédito gobierno de izquierda elegido en 2002 negoció a comienzos del mandato la entrada del PMDB en la coalición, lo que aumentó la bancada en más de $14,4 \%$, alcanzando casi el requisito de los 3/5 para introducir cambios en el texto constitucional. La participación formal mediante la ocupación de carteras ministeriales no se consumó, pero aun así, el gobierno contó con el apoyo del PMDB y del PP a la agenda presidencial, durante los dos primeros años de gobierno.

13 Según Meneguello (1998), la necesidad de adecuar la formación ministerial a la heterogeneidad de intereses lleva a los gobiernos a modificar, con bastante frecuencia, la estructura organizacional de los órganos ministeriales -aumentando su número, desmembrando ministerios-, un hecho que considera más la presión de la diversidad de intereses que la sujeción a criterios propiamente técnicos. 
Cuadro 1. Gabinetes presidenciales

\begin{tabular}{|c|c|c|c|c|c|}
\hline $\begin{array}{l}\text { Presidente y } \\
\text { Gabinete }\end{array}$ & $\begin{array}{l}\text { Duración del } \\
\text { gobierno }\end{array}$ & $\begin{array}{l}\text { Partidos representados en } \\
\text { el ministerio }\end{array}$ & $\begin{array}{c}\text { Tasa de } \\
\text { coalescencia }^{14}\end{array}$ & $\begin{array}{c}\text { Tamaño (\%) } \\
\text { nominal del } \\
\text { gabinete - CD }\end{array}$ & $\begin{array}{l}\% \text { ministros } \\
\text { sin filiación } \\
\text { partidaria }\end{array}$ \\
\hline Sarney I & $03 / 85-02 / 86$ & PMDB-PFL-PTB-PDS & 0,66 & 93,5 & 18 \\
\hline Sarney II & $02 / 86-01 / 89$ & PMDB-PFL & 0,64 & 69,3 & 14 \\
\hline Sarney III & $01 / 89-03 / 90$ & PMDB-PFL & 0,41 & 53,3 & 35 \\
\hline Collor I & $03 / 90-10 / 90$ & PMDB-PFL-PRN & 0,40 & 50,3 & 60 \\
\hline Collor II & $10 / 90-01 / 92$ & PFL-PDS-PRN & 0,40 & 29,6 & 60 \\
\hline Collor III & $01 / 92-04 / 92$ & PFL-PDS & 0,30 & 26,2 & 60 \\
\hline Collor IV & 04/92 - 10/92 & PFL-PDS-PSDB-PTB-PL & 0,46 & 43,7 & 45 \\
\hline Itamar I & $10 / 92-01 / 93$ & $\begin{array}{l}\text { PMDB-PFL-PSDB-PTB- } \\
\text { PDT-PSB (s/partido) }\end{array}$ & 0,62 & 61,6 & 20 \\
\hline Itamar II & $01 / 93-05 / 93$ & $\begin{array}{c}\text { PMDB-PFL-PSDB-PTB- } \\
\text { PDT-PSB-PT }\end{array}$ & 0,59 & 67,4 & 38 \\
\hline Itamar III & $05 / 93-09 / 93$ & $\begin{array}{c}\text { PMDB-PFL-PSDB-PTB- } \\
\text { PSB }\end{array}$ & 0,51 & 53,3 & 38 \\
\hline Itamar IV & $09 / 93-01 / 94$ & $\begin{array}{l}\text { PMDB-PFL-PSDB- } \\
\text { PTB-PP }\end{array}$ & 0,48 & 58,6 & 52 \\
\hline Itamar $\mathrm{V}$ & $01 / 94-01 / 95$ & PMDB-PFL-PSDB-PP & 0,22 & 55,3 & 76 \\
\hline FHC I (1) & $01 / 95-04 / 96$ & PSDB-PMDB-PFL-PTB & 0,57 & 56,3 & 32 \\
\hline FHC I (2) & $04 / 96-12 / 98$ & $\begin{array}{c}\text { PSDB-PMDB-PFL-PTB- } \\
\text { PPB-PPS }\end{array}$ & 0,60 & 76,6 & 32 \\
\hline FHC II (1) & $01 / 99-03 / 99$ & $\begin{array}{c}\text { PSDB-PMDB-PFL-PTB- } \\
\text { PPB-PPS }\end{array}$ & 0,70 & 74,3 & 23,8 \\
\hline FHC II (2) & $03 / 99-10 / 01$ & $\begin{array}{c}\text { PSDB-PMDB-PFL-PPB- } \\
\text { PPS }\end{array}$ & 0,59 & 68,2 & 37,5 \\
\hline FHC II (3) & $10 / 01-03 / 02$ & PSDB-PMDB-PFL-PPB & 0,68 & 62,0 & 31,6 \\
\hline FHC II (4) & $03 / 02-12 / 02$ & PSDB-PMDB-PPB & 0,37 & 45,1 & 63,2 \\
\hline Lula I & $01 / 03-12 / 03$ & $\begin{array}{l}\text { PT-PSB-PDT-PPS- } \\
\text { PCdoB-PV-PL-PTB }\end{array}$ & 0,64 & 49,3 & 17,2 \\
\hline
\end{tabular}

Fuente: Amorim Neto (2004).

14 Amorim Neto (2000) usa el indicador tasa de coalescencia para señalar el desvío de proporcionalidad de la relación entre puestos ministeriales y el tamaño de las diversas bancadas en la Cámara. El índice varía de 0 , que señala nula correspondencia entre las variables, a 1 , que indica una asignación perfectamente proporcional. Ver la columna tasa de coalescencia del Cuadro 4. La última columna del cuadro indica el porcentaje de ministerios en que los ocupantes no están afiliados a partido político alguno. 
Por otra parte, más allá de los criterios partidarios, los gobiernos también se empeñan en responder a la diversidad federativa (Abranches, 1988; Menegue1lo, 1998). Tanto en el medio periodístico como en el académico, son comunes las referencias relativas a la influencia de los gobernadores sobre las bancadas parlamentarias en la Cámara. Según Meneguello, con respecto a la formación ministerial, "es posible observar que la composición partidaria de las coaliciones gubernamentales federales acompaña el control partidario de los gobiernos estaduales en el período" (Meneguello, 1998: 77). Los subsistemas partidarios regionales son, por lo tanto, otro parámetro relevante en la construcción de mayorías gubernativas. Cada vez más, la región del sureste ha sido la mayor beneficiaria a lo largo del período en el proceso de formación ministerial -en el gobierno FHC, la región llegó a ocupar un 67\% de los ministerios- seguida, en menor medida, por la región del noreste (Meneguello, 1998).

En consecuencia, en el caso brasileño se comprueba que casi todos los "gabinetes" comandan una mayoría nominal en la Cámara. Pero ¿qué sucede con los niveles de disciplina partidaria? En las diversas coaliciones analizadas por Amorim Neto (2000), la disciplina partidaria dependió principalmente de tres tipos de factores: del grado de coalescencia en los ministerios, esto es, de la obtención de puestos ministeriales en relación con el tamaño de la respectiva bancada en la Cámara; del desarrollo del mandato presidencial; y, según el partido, de la distancia ideológica respecto del Ejecutivo ${ }^{15}$. El resultado final indica que una mayor proporcionalidad entre la presencia de los partidos en los ministerios y su contribución en escaños para la coalición gubernamental en el Legislativo, tiene efectos positivos sobre la disciplina de los partidos gobernantes. No obstante, tal disciplina va decreciendo durante el transcurso del mandato presidencial. Además de la distribución de ministerios ${ }^{16}$, las prerrogativas del Presidente y de los líderes partidarios constituyen factores que inducen a los parlamentarios a cooperar. Este será el tema de la próxima sección.

15 Hay algunas premisas subyacentes a las hipótesis que conviene esclarecer. La hipótesis principal -cuanto mayor el grado de coalescencia, más disciplinado será el comportamiento de los partidos pertenecientes a la coalición gobernante- implica motivaciones de "búsqueda de cargos". Sin embargo, los partidos también tienen otras motivaciones: maximización de votos y/o de políticas. La primera hipótesis es verificada por la hipótesis 2: a medida que avanza el mandato disminuye la disciplina debido a que, en razón de consideraciones electorales futuras, se van formando facciones de oposición. Por su parte, la maximización de políticas es verificada por la hipótesis 3: cuanto más diversa es la composición ideológica de la coalición, más baja es la disciplina.

16 "La escasa autonomía del poder legislativo en la formulación de políticas públicas vuelve la participación en el gobierno aún más importante para los parlamentarios interesados en garantizar su reelección. Este control de cargos proporciona mecanismos que permiten así fomentar la disciplina partidaria. Los parlamentarios pueden incurrir en costos, votando a favor de medidas contrarias a sus intereses inmediatos en función de las ganancias que pueden granjear como miembros de la coalición de gobierno", en Figueiredo y Limongi (1999), p. 38. 


\section{Poderes de agenda del Presidente}

La Constitución brasileña de 1988 mantuvo varios instrumentos de control del proceso legislativo en manos del Ejecutivo, instrumentos creados durante la dictadura militar vigente entre 1964 y 1985, lo que ha afectado drásticamente el equilibrio entre los poderes. Como prueban los indicadores -relativos a la proporción de leyes iniciadas y aprobadas por cada administración-; en el período anterior a $1964^{17}$ el Ejecutivo presentaba tasas de éxito en torno al 30\%. En el período posterior a 1988, este índice se invierte. Más impresionante aún es la gran variación que experimenta esta cifra, del 9,8\% al 45\%, entre los diferentes gobiernos del primer período (1946-64); mientras que bajo la actual carta Constitucional se observa, por el contrario, una mayor estabilidad o una menor variación en las tasas de éxito (entre $65,4 \%{ }^{18}$ y $72 \%$ ). Lo anterior pareciera indicar que, a pesar de los factores circunstanciales, los nuevos factores institucionales han ejercido un peso importante (Figueiredo, 2000).

Igualmente, el período actual se diferencia por el mayor grado de disciplina de los partidos pertenecientes a la coalición de gobierno. Parte de la explicación se encuentra en el hecho de que la agenda se origina en su casi totalidad en el Ejecutivo, siendo generalmente aprobada en régimen de urgencia, lo que la convierte en una agenda impuesta ${ }^{19}$. La gran diferencia entre ambos períodos democráticos reside en que el patronazgo, entendido como la distribución de segmentos del acervo estatal (ministerios, empresas estatales, secretarías, etc.) a los partidos como una forma de procurar apoyo, acompañado del poder de agenda, proporciona una base más segura de sustentación ${ }^{20}$ parlamentaria que el recurso aislado al primero. Los actuales poderes de agenda del Presidente emanan del monopolio del Ejecutivo en el inicio de proyectos (en el área presupuestaria y administrativa), en el recurso a pedidos de urgencia y, principalmente, en la posibilidad de emitir medidas provisorias que cobran vigencia inmediata a partir de su publicación ${ }^{21}$.

Figueiredo y Limongi (1999) suministran evidencias de que la tasa de aprobación de aquellas legislaciones en que el Ejecutivo tiene el monopolio de la inicia-

17 Período anterior a 1964, que se refiere al régimen democrático vigente entre 1946 (cuando fue derribado el régimen dictatorial de Getúlio Vargas) y 1964 (año del golpe militar que instauró el régimen autoritario hasta 1985).

18 Esa tasa menor ocurrió durante el gobierno Collor.

19 Para la comparación entre el período actual y el de 1946-64, ver Santos (2003a).

20 "Es lícito suponer, entonces, que la dinámica de la interacción Ejecutivo-Legislativo asumirá un carácter enteramente distinto ante la falta del poder de agenda a favor del Presidente. Sin que sea posible al gobierno manipular estratégicamente la distribución de preferencias de los diputados y ocupar la agenda del plenario, quitando tiempo para la tramitación de asuntos originados en el Legislativo, se puede imaginar un escenario de extrema incertidumbre para las pretensiones del Presidente. No sólo los diputados adquieren una mayor influencia legislativa, sino también la tasa de cooperación con el Presidente tiende a ser sistemáticamente menor", en Santos (1997), p. 477.

21 El Presidente también tiene el poder de veto total o parcial en relación con las leyes aprobadas por el Congreso, que pueden ser abolidas por mayoría absoluta. 
tiva es altísima. En efecto, sólo cuatro leyes referentes a materias presupuestarias (pedido de apertura de crédito) fueron rechazadas en 10 años en la Cámara. A su vez, el derecho de requerir la urgencia legislativa le otorga al Presidente ciertas ventajas estratégicas, lo que impacta de manera favorable en la tasa de aprobación de las leyes. A través de la urgencia, el Presidente puede: 1) estipular plazos para el conocimiento del proyecto de ley en cuestión, con independencia de su complejidad y de los intereses implicados 22 ; 2) alterar el flujo legislativo ordinario, ya que a través de la urgencia el proyecto es discutido directamente en la Cámara de origen y no es sometido al conocimiento previo de la Comisión respectiva; 3) Distribuir a su favor el tiempo legislativo, ya que la urgencia impone al Congreso la discusión de materias de iniciativa presidencial en desmedro de sus propios proyectos. En consecuencia, el pedido de urgencia permite la intervención del Ejecutivo en la agenda legislativa, por encima de la voluntad de los parlamentarios, en cuanto dicha solicitud no es sometida a votación. Como puede observarse, se trata de un caso muy distinto al norteamericano donde el Legislativo controla la agenda de forma autónoma ${ }^{23}$ (Amorim Neto, Cox y McCubbins, 2003).

Medidas Provisorias. Los poderes de agenda anteriores tienen efectos modestos si se comparan con aquellos procedentes de las medidas provisorias (MP), o sea, referentes a la capacidad del Ejecutivo de emitir decretos con fuerza de ley inmediata y sin consulta al Legislativo. Su uso, al inicio, se limitaba a cuestiones de urgencia y relevancia. Pero, con el tiempo, pasó a englobar incluso asuntos administrativos y ordinarios. De acuerdo con la Constitución de 1988, las MP entrarían en vigencia a partir de la fecha de su publicación aunque, para efectos de su eficacia, deberían ser sometidas a discusión por el Congreso dentro de los 30 días siguientes. Sin embargo, la reedición de tales medidas por parte del Ejecutivo se convirtió en una práctica frecuente, logrando así burlar la obligación legal de someterlas a votación. A través de este mecanismo se evitaba que el Ejecutivo incurriese en los costos de formación de mayorías; costos que, por el contrario, eran traspasados al Legislativo.

Comprendidos los aspectos básicos de las MP, se abre el debate, entonces, sobre sus consecuencias en el patrón de relación entre el Ejecutivo y el Legislativo. Ese patrón depende mucho de las estrategias escogidas por el Presidente. Si opta por montar un gobierno de coalición concediendo puestos ministeriales en función de la fuerza de los partidos en el parlamento, es probable que, al emitir MP, tratará de observar el interés de la mayoría gubernamental que le da sustentación (y tratará de gobernar por medios ordinarios). El caso del gobierno

22 Una vez solicitada la urgencia, cada una de las Cámaras deberá pronunciarse sucesivamente sobre el proyecto de ley dentro de un plazo total 45 días. Si no se pronuncian dentro de dicho plazo, el proyecto se incluye de manera automática y prioritaria en el orden del día para su votación.

23 "Brasil, junto con algunos otros países latinoamericanos, es, por ende, diferente en términos de la capacidad que tiene un actor externo de establecer la agenda legislativa. De manera plausible, el poder de la agenda residual que permanece en el poder legislativo es un pastel más pequeño por dividir, y, por ende, menos valioso y estabilizador", en Amorim Neto, Cox y McCubbins (2003). 
de FHC es emblemático pues, además de montar un gabinete con un grado razonable de coalescencia, permitió que los textos legales de diversas reediciones sufriesen alteraciones negociadas (Amorim Neto y Tafner, 2002). Collor dio el ejemplo opuesto, al formar durante su primer año de gobierno un ministerio no incluyente y abusar de la edición de MP originales. El Congreso, por su parte, reaccionó ante dicha práctica poniendo en discusión una ley dirigida a regular la utilización de este particular poder de agenda. Este hecho repercutió de manera directa sobre el Presidente, disminuyendo su ímpetu de tratar de gobernar unilateralmente (Power, 1998).

Por otro lado, las medidas provisorias tenían el efecto de proteger a los miembros de la coalición de la repercusión de medidas impopulares. Según Figueiredo (2000), con las reediciones, los líderes partidarios no asumían directamente la responsabilidad pública por la aprobación de las MP, aun cuando participasen en las modificaciones hechas en el texto legal. Por ello, las frecuentes reediciones no pueden, además, ser consideradas como una abdicación por parte del Legislativo.

El poder de la agenda y el control sobre el proceso legislativo permite a los gobiernos proteger su mayoría contra decisiones impopulares y preservar los acuerdos sobre políticas. En este sentido, fomentan una acción concertada entre el gobierno y su mayoría de apoyo y, en consecuencia, aumentan la cooperación (Figueiredo, 2000: 12).

No obstante, en el 2001 el Congreso Nacional aprobó el proyecto de Enmienda Constitucional No. 32, confiriendo una nueva reglamentación al uso de las Medidas Provisorias. Conforme a la nueva metodología, las MP pasaron a tener validez por 60 días, prorrogables por otros sesenta, al término de los cuales el Congreso era obligado a manifestarse en hasta 45 días, bajo pena de dar por suspendida su pauta de discusión. El propósito de la PEC 32 era mitigar el ímpetu del Ejecutivo en legislar vía las MP. Se suponía que los gobiernos seleccionarían medidas relevantes y urgentes, con el fin de no paralizar los trabajos legislativos. Sin embargo, y como generalmente ocurre con aquellas materias relacionadas con reformas políticas, la realidad se mostró bastante diferente. La nueva regla, en vez de tener un efecto inhibidor, produjo un mayor número de emisiones tanto al final del gobierno de FHC como en el actual gobierno de Lula. Al mismo tiempo, se advirtió un hecho más bien raro bajo la antigua regla: fueron rechazadas $14 \mathrm{MP}$ en el gobierno de FHC y, hasta ahora, 7 en el gobierno de Lula -lo que corrobora el punto respecto al manto protector del mecanismo de las reediciones-. En resumen, la eliminación de la posibilidad de reedición, así como la obligatoriedad de la manifestación del plenario, conllevan la posibilidad de un conflicto abierto y público -un hecho que refuerza la caracterización del Congreso como una Cámara transformadora-.

El siguiente cuadro presenta las MP emitidas en cada gobierno, con los respectivos promedios mensuales, y revela, además, el contraste entre la emisión de las MP bajo la antigua reglamentación y la actual -la PEC No. 32-. 


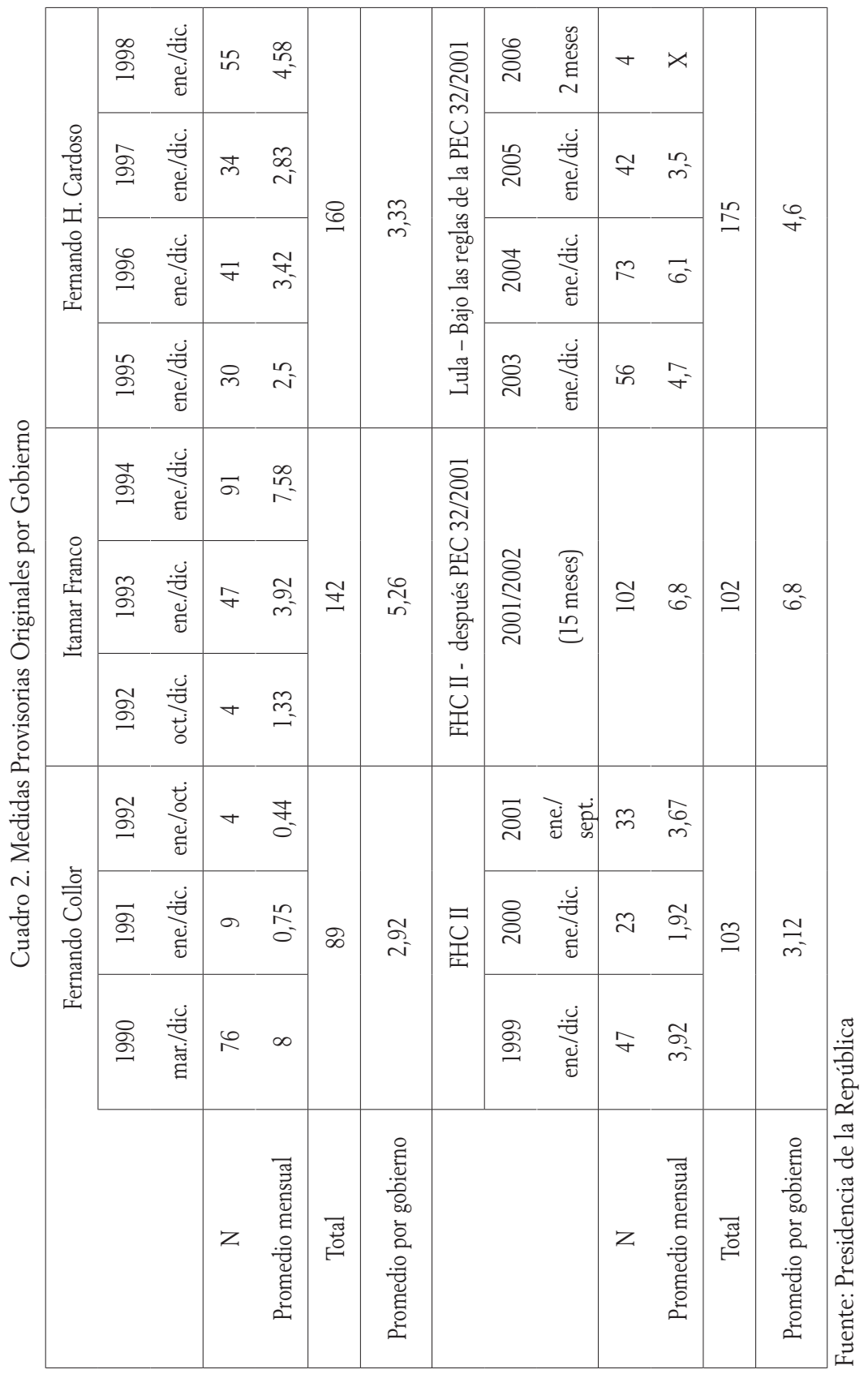


Si tomamos como base los dos primeros años de su mandato, el gobierno de Lula $^{24}$, en promedio, emitió muchas más MP que los gobiernos anteriores. Los datos son más impresionantes si consideramos la excepcionalidad de los años de implantación de los planes de estabilización en 1990 y 1994, que empujaron hacia arriba los promedios de los gobiernos de Collor e Itamar. En este sentido, los números absolutos de esos años se podrían justificar bajo la óptica de la relevancia y de la urgencia. Sin embargo, un análisis cuidadoso del cuadro nos revela que ese hecho puede tener más que ver con el nuevo tipo de reglamentación de las MP que con la titularidad en la presidencia. En otras palabras, ocurrió un mayor número de emisiones conforme a las reglas de la PEC No. 32 al final del mandato de FHC e inicios del gobierno Lula ${ }^{25}$.

Considerando el renovado ímpetu de Lula en seguir emitiendo un gran número de MP, bajo el funcionamiento de las reglas de la PEC No. 32, los parlamentarios buscaron una vez más proponer un nuevo freno institucional. Estas propuestas de una nueva PEC para regular las MP provinieron de diputados de tanto fuera como dentro de las bases de apoyo del gobierno. El hecho no es sorprendente, pues Lula no sólo mantuvo el mismo patrón de los gobiernos anteriores, en cuanto al uso de las MP para legislar sobre materias no relevantes y urgentes, sino que incluso excedió su número ${ }^{26}$.

\section{Centralización decisoria en el Legislativo}

Otro factor que ayuda a concentrar el proceso de formulación de políticas públicas es la centralización del proceso legislativo ordenado por el Reglamento Interno de la Cámara de Diputados. En la Cámara de Diputados, la distribución de derechos parlamentarios se efectúa según criterios partidarios: el principio de la proporcionalidad partidaria determina la composición de la Mesa Directiva y la distribución de los parlamentarios en las comisiones. El reglamento reconoce la existencia del Colegio de Líderes ${ }^{27}$, instancia decisoria que actúa de manera

24 A partir del tercer año, el gobierno tuvo su agenda estancada debido a las acusaciones de corrupción y las investigaciones de las Comisiones Parlamentarias de Indagación.

25 Este aspecto, vale decir los efectos no anticipados de la PEC No. 32, merecerá un análisis más detallado en otra oportunidad.

26 Debemos reiterar, tras el análisis del contenido de las proposiciones, que no habría motivos que justifiquen el excesivo número de emisiones de MP en el gobierno Lula.

27 El Colegio de Líderes es un órgano decisorio compuesto por los liderazgos partidarios y el jefe del gobierno. Sus decisiones se deben dar por consenso. Si esto no ocurre, los votos de los líderes pasan a tener un peso proporcional a su bancada, obteniéndose bajo ese criterio la mayoría absoluta. Ver al respecto Pacheco y Mendes (1998). Existe desacuerdo, sin embargo, acerca de la importancia del Colegio de Líderes: "As a forum for multiparty negotiations and bargaining, the colégio was most active on unidimensional issues where lines of compromise were clear. On more complex, multidimensional issues, major actors must actively have sought compromise before the colégio could play a role. Issues involving powerful states had to be resolved by the states and the executive before party leaders got involved", en Ames (2001), p 242. 
centralizada en la determinación de la pauta de los trabajos legislativos, junto con el Presidente de la Mesa Directiva.

En la práctica, los líderes ${ }^{28}$ controlan el flujo de trabajos legislativos y los encaminan al Plenario, que pasa a ser el principal locus decisorio, neutralizando así las comisiones como locus de poder descentralizado. Esto se efectúa a través del pedido de urgencia que retira la ley de la comisión competente y la envía inmediatamente al plenario. A diferencia de la urgencia constitucional, esta solicitud debe ser votada y aprobada aunque, en compensación, sus plazos son bastante menores ${ }^{29}$. Para el pedido son necesarios $1 / 3$ de los miembros de la Cámara o el apoyo de los líderes que representen ese número, o 2/3 de los miembros de una comisión o de la Mesa Directiva. En la práctica, esa prerrogativa acaba restringiéndose a los líderes, pues existen problemas evidentes de coordinación y formación de mayorías, el tiempo es reducido y es difícil reunir el contingente necesario antes de que el tema se dé por cerrado. Así, los parlamentarios tienen una capacidad muy reducida de dirigir los trabajos legislativos de manera individual, lo que contrasta con la firma del líder, que es representativa, o sea, suficiente para expresar la voluntad del partido (Figueiredo y Limongi, 1999). El pedido de urgencia limita, también, el derecho de proponer enmiendas en el plenario; es necesario 1/5 de los miembros para garantizarlo. La mayoría de los pedidos de urgencia se efectúa en el interés del Ejecutivo, siendo que, aproximadamente, un 70\% de los mismos es realizado por el propio Congreso (Pereira y Mueller, 2000). Otro hecho interesante que avala el papel de los liderazgos en el período 1995-98 es que cuanto más extrema sea la inclinación ideológica de la comisión que analiza un asunto visà-vis las preferencias del plenario, mayor será la probabilidad de la utilización del pedido de urgencia (Pereira y Rennó, 2001).

El nombramiento de parlamentarios para las comisiones es realizado por la Mesa Directiva, de acuerdo con la indicación de los líderes partidarios. Según Santos (2003a), la selección de aquellos que van a componer las comisiones se basa en la lealtad de los miembros a la posición del partido en las votaciones en el plenario. No obstante, éste no es el único criterio, pues los líderes se preocupan también por la calidad informativa de las leyes, principalmente, en lo relativo a las comisiones claves. Por lo tanto, al momento de conformar las comisiones, los líderes no sólo toman en cuenta la lealtad partidaria, sino

28 Según el reglamento interno, los líderes pueden hacer uso de la palabra durante las sesiones por un tiempo proporcional al tamaño de su bancada; pueden participar -sin derecho a voto- en los trabajos de cualquier comisión; pueden encaminar votaciones en plenario; escoger los miembros para componer las comisiones; registrar los candidatos del partido aptos para concurrir a los cargos de la Mesa; inscribir a miembros para las comunicaciones parlamentarias antes de la orden del día y, también, escoger a los vicelíderes de su bancada. Ver Pacheco y Mendes (1998).

29 En la Constitución de 1946: “(...) the lower chamber's standing orders did not allow legislative leaders to send bills to more than one standing committee. This implies that legislative leaders could not oppose the gate-keeping power of committees. Moreover, legislative leaders did not posess institutional mechanism by which they could withdraw proposal from committees and send them to the floor", en Amorim Neto y Santos (2001). 
también la "policy expertise"30; esto es, la especialización previa de los parlamentarios.

En la Cámara, las dos comisiones que cumplen con este requisito y que son de suma importancia tanto para la agenda presidencial como para los miembros de la coalición gubernamental, son las Comisiones de Constitución y Justicia y de Redacción, responsables de la constitucionalidad de las leyes aprobadas; y la Comisión de Finanzas y Tributación, responsable de las leyes que tienen impacto fiscal en cuanto afectan las políticas distributivas. Ambas comisiones tienen poder de veto sobre la apreciación de las leyes (Santos 2003a). La preocupación para los partidos, en virtud de su posición estratégica, es la de sugerir para la presidencia de esas comisiones a líderes cuyas preferencias sean representativas del partido. En el trabajo de Pereira y Mueller (2000) se verificó que, en la composición de la mayoría de las comisiones en el período de 1995 a 1998, el integrante promedio presentaba altos índices de lealtad al Ejecutivo. Esto implica que la coalición gobernante dispone de un mecanismo óptimo para impedir la discusión (o el conocimiento) de leyes contrarias a sus intereses y, asimismo y de manera complementaria, evitar confrontaciones en el plenario. Esos no son los únicos mecanismos de los que disponen los líderes partidarios vis-à-vis las comisiones, pues los líderes pueden sustituir a sus miembros en cualquier momento ${ }^{31} \mathrm{o}$ incluso debilitar las comisiones permanentes mediante la creación de comisiones especiales ${ }^{32}$ (Pereira y Mueller, 2000).

Las comisiones ${ }^{33}$ y el plenario pierden su carácter de instancias decisorias en la medida en que las discusiones sustantivas son deliberadas en el Colegio de Líderes. La participación de los parlamentarios es entonces restringida a la fase final del pro-

30 Para los líderes, existe preocupación respecto de la reputación colectiva del partido. Así, los nombramientos para comisiones con amplias jurisdicciones -aquéllas cuyo impacto afecta la imagen pública del partido-y altas exterioridades (sus decisiones afectan a miembros que no participan de la comisión) son objeto de interés primordial para los líderes.

31 Las comisiones presentan significativas tasas de rotación, lo que dificulta el desarrollo endógeno de expertise.

32 Las comisiones especiales son obligatorias cuando se sobreponen jurisdicciones o estuvieran en tramitación proyectos de enmiendas constitucionales.

33 Sólo para enfatizar: el papel sobresaliente de los líderes partidarios no depende, exclusivamente, del Colegio de Líderes, sino que obedece, además, al peso ponderado de sus firmas para pedidos, a los predominios de votación y a la presentación de enmiendas. Pero, principalmente, dicho rol se expresa a través de los pedidos de urgencia, los cuales son concertados antes de llegar al plenario. La solicitud de urgencia altera el flujo normal de tramitación de las materias, retirándolas de las comisiones e incluyéndolas en la orden del día; lo que dificulta la apreciación crítica de su contenido por el plenario al despojar a las comisiones de su prerrogativa decisoria. Por otro lado, conviene anotar que los constituyentes habían dotado a las comisiones de poder terminal, es decir, del poder de aprobar proyectos como instancia final sin pasar por el plenario, salvo en el caso de existir un recurso en contra. Lo anterior tenía como objetivo descentralizar y descongestionar la carga de trabajo en el plenario y asegurar una mejor calidad en el conocimiento de los proyectos mediante mayor especialización. Las comisiones como instancia primera y obligatoria de paso de los proyectos, donde se emiten pareceres y se seleccionan aquéllos aptos para la consideración del plenario, no dejan de tener su función técnica. Sin embargo, los datos evidencian que apenas un 29\% de las leyes pasan por el flujo ordinario (hasta llegar al plenario) y sólo un $16 \%$ son aprobadas en carácter terminal. La inmensa mayoría se tramita en régimen de urgencia (de 1988 a 1994, cerca de 55\%) y, en su mayoría urgencia urgentísima; sin tomar en cuenta el trabajo de las comisiones. Ver Figueiredo y Limongi (1999). 
ceso, cuando la ley es sometida a votación. La centralización en el Colegio de Líderes favorece al Ejecutivo, en cuanto disminuye las incertidumbres propias de un proceso de negociación descentralizado (Figueiredo y Limongi, 1999). No obstante, dicha circunstancia opera en función de la disposición que tenga el Presidente para organizar su ministerio y su base de sustentación legislativa sobre criterios partidarios.

Otro buen indicador del reducido derecho de los parlamentarios es el brevísimo tiempo de tramitación de los asuntos aprobados, que indicaría que éstos se limitan a votar materias previamente acordadas entre los líderes y el Ejecutivo. Además, las leyes introducidas por el Legislativo, a través de iniciativas individuales de los parlamentarios, se demoran tres veces más en ser aprobadas que las del Ejecutivo. Estos problemas de selección y de apreciación en razón de la cantidad de proyectos y del tiempo requerido para su aprobación, sugieren que la organización legislativa no se encuentra optimizada para tratar las iniciativas individuales de los parlamentarios (Figueiredo y Limongi, 1999).

\section{Los partidos políticos en la Cámara de Diputados}

Las dos secciones siguientes se dedicarán al estudio de las consecuencias del presidencialismo de coalición en términos de comportamiento partidario. Nos interesa desarrollar dos temas en particular: la disciplina partidaria y la elección de los liderazgos partidarios en las votaciones en plenario.

Figueiredo y Limongi (1999) observaron que era posible, siguiendo la designación de los líderes partidarios en el período 1989-1998, ordenar los partidos en el siguiente continuum ideológico: PPB, PFL, PTB en la derecha; PMDB y PSDB como partidos de centro; PDT y PT como partidos de izquierda -disposición que es consistente con otros estudios. La idea que sugiere esta ordenación es que los partidos adyacentes tienen mayor probabilidad de encaminar votos similares, y esa probabilidad disminuye a medida que aumenta la distancia entre los mismos- considerando aquella ordenación como la disposición ideológica de los partidos en un espacio unidimensional. En líneas generales, y considerando el contraste, durante ambos mandatos de FHC, entre la coalición de gobierno, de centro-derecha, y la oposición, podemos aceptar esta hipótesis; agregándole, además, el hecho de que la representación de los citados partidos en la Cámara alcanzaba casi el 90\% de los escaños.

Es posible rebatir este método ${ }^{34}$ para el segundo mandato de FHC y para los dos primeros años del gobierno de Lula, con la diferencia de que se incluyen ahora dos partidos -el PL y el PSB-. Estos partidos representaban menos del 6\% de los escaños en la Cámara durante el período 1994-2001, logrando una mejora en

34 La muestra utiliza las votaciones que presentan algún nivel de conflicto en plenario, eliminando aquéllas consensuales. Una votación es definida como consensual si los líderes de los principales partidos -PT, PFL, PMDB, PSDB, PP, PTB, PL, PSB y PDT- dan la misma consigna de votos y, al mismo tiempo, cuando no existe la oposición de al menos un $10 \%$ del plenario. No obstante, conviene advertir al lector 
esta participación de un 10\% durante el gobierno de Lula. O sea, la inclusión de ambos partidos se debe a la importancia que adquirieron recientemente.

El patrón de contraste entre la centro-derecha y la izquierda, considerando la indicación de voto de los liderazgos, es semejante en ambos mandatos de FHC. El examen del cuadro siguiente confirma la hipótesis de la consistencia ideológica en el segundo mandato del Presidente FHC, mas no en el gobierno de Lula. Durante el liderazgo del PL en el período 1999-2002, la mayoría de las veces dio a su bancada indicaciones de voto conjuntamente con la izquierda, a pesar de que en ese interin era un partido irrelevante, que representaba en promedio un 2,4\% delos escaños en la Cámara, al contrario de lo que acontece durante el actual gobierno del Presidente Lula.

Cuadro 3. Indicaciones similares de voto por los liderazgos partidarios
\begin{tabular}{|ccccccccc|}
\hline \multicolumn{10}{c}{ Gobierno de FHC II (1999-2002) } \\
\cline { 2 - 9 } & PFL & PTB & PL & PSDB & PMDB & PDT & PSB & PT \\
\hline PPB & 93 & 82 & 39 & 95 & 94 & 16 & 13 & 21 \\
PFL & & 79 & 40 & 94 & 92 & 18 & 16 & 22 \\
PTB & & & 42 & 83 & 81 & 32 & 23 & 31 \\
PL & & & & 39 & 41 & 69 & 69 & 65 \\
PSDB & & & & & 97 & 20 & 17 & 25 \\
PMDB & & & & & & 21 & 17 & 26 \\
PDT & & & & & & 82 & 82 \\
PSB & & & & & & & \\
\hline
\end{tabular}

\begin{tabular}{|c|cccccccc|}
\hline \multicolumn{7}{|c|}{ Gobierno de Lula (2003-2004) } \\
\cline { 2 - 9 } & PFL & PTB & PL & PSDB & PMDB & PDT & PSB & PT \\
\hline PPB & 27 & 90 & 88 & 32 & 88 & 78 & 86 & 87 \\
PFL & & 22 & 23 & 74 & 26 & 27 & 18 & 19 \\
PTB & & & 95 & 25 & 92 & 85 & 94 & 94 \\
PL & & & & 27 & 92 & 87 & 92 & 93 \\
PSDB & & & & & 30 & 28 & 22 & 23 \\
PMDB & & & & & & 82 & 89 & 90 \\
PDT & & & & & & & 87 & 88 \\
PSB & & & & & & & & 98 \\
\hline
\end{tabular}

Fuente: Banco de datos NECON.

que fueron necesarias algunas adaptaciones. Por eso son seguras las observaciones de las tendencias generales dentro de cada mandato, mas no tan rigurosas cuando se comparan gobiernos diferentes. Por ejemplo, podemos observar que el PL en el segundo mandato FHC II, votó la mayoría de las veces con la izquierda, aunque no resulta tan aconsejable comparar la diferencia numérica entre este mandato y el de Lula. En este último, los partidos de oposición hicieron constantemente obstrucción. 
Este patrón de consistencia se deshace justamente con la asunción a la presidencia de un partido fuertemente estructurado e ideológico -el PT- al incorporar dos partidos de derecha a la coalición de gobierno, el PL y el PTB. Además, otro partido de derecha, el PPB, también se alinea con el gobierno en las votaciones, aunque sin participación en los ministerios. El PMDB, como de costumbre, sigue a remolque del gobierno. La popularidad del gobierno y la atracción ejercida por el Ejecutivo pueden ser la explicación de esa alineación informal de los dos últimos partidos. A su vez, el PSDB y el PFL mostraron un bajo nivel de coordinación en el primer año, indicando direcciones similares en apenas un $61 \%$ de las votaciones (y $86 \%$ en el segundo).

Se percibe de inmediato que ocurre un fenómeno bien interesante en el gobierno de Lula: si durante todo el período de redemocratización, pasando por los gobiernos de Sarney, Collor, Itamar Franco y FHC, predominó un claro patrón ideológico en la forma en que los líderes se posicionaban frente a las cuestiones sometidas a votación, esto ya no se verifica en el período que se inicia en enero. El patrón actual sufre una alteración significativa, ya que el tono del posicionamiento de los partidos deja de ser ideológico, convirtiéndose más propiamente en gobierno (con partidos de izquierda y derecha) e independientes (PMDB y $\mathrm{PPB}$ ) versus oposición.

\section{Disciplina partidaria}

De acuerdo con una parte significativa de la literatura especializada, el sistema electoral brasileño de representación proporcional con lista abierta conduce al costo de generar partidos débiles y una política personalizada, que se refleja en una indisciplina generalizada dentro de la arena legislativa. El PR brasileño debilitaría, entonces, el control partidario en el momento electoral -durante la campaña- y posteriormente en el control del comportamiento de los diputados en el Legislativo, e impediría el surgimiento de un agregado de intereses coherentes. Otra vertiente adoptada inicialmente por autores como Figueiredo y Limongi (1999), insiste en la tesis de que la imposibilidad de castigar a los miembros indisciplinados en el Congreso no implica una irrelevancia del partido. Como hemos visto, el Presidente y los líderes partidarios poseen una serie de prerrogativas decisorias que inducen a los parlamentarios a un comportamiento cooperativo.

El Cuadro 4 presenta el porcentaje promedio de diputados que declararon el mismo voto que el liderazgo partidario. Hay diversas formas de interpretar estos datos. Una de ellas es afirmar que los índices de disciplina son mayores que aquellos encontrados en el período 1946-1964. Santos (1997) sostiene que la diferencia fundamental entre los períodos reside en que, a partir de la Constitución de 1988, el patrocinio conjugado con los poderes de agenda ayudó a construir una base más segura de apoyo parlamentario e incidió de manera más incisiva sobre la disciplina partidaria. Contrasta también el cambio de una agenda compartida, en la primera experiencia democrática, a una agenda impuesta, originada 
Cuadro 4. Disciplina partidaria ${ }^{35}$ por gobierno (\%)

\begin{tabular}{|c|c|c|c|c|c|c|}
\hline & Sarney & Collor & Itamar & FHC I & FHC II & Lula \\
\hline & $1986-1989$ & $1990-1992$ & 1993 & $1994-1998$ & $1999-2002$ & $2003-2004$ \\
\hline PT & 98,8 & 96,7 & 97,8 & 97,1 & 98,9 & 95,8 \\
\hline PDT & 93,5 & 92,9 & 91 & 91,5 & 94,3 & 86,4 \\
\hline PSDB & 86,8 & 88,3 & 87 & 92,9 & 96,4 & 84,6 \\
\hline PFL & 88,2 & 90,3 & 87,4 & 95,1 & 95 & 84,3 \\
\hline PPB & 85,2 & 90,9 & 87,4 & 84,3 & 91,2 & 83,7 \\
\hline PTB & 79,5 & 84,6 & 83,9 & 89,7 & 87 & 91,3 \\
\hline PMDB & 83,7 & 87,5 & 91,2 & 82,3 & 86,8 & 83,1 \\
\hline Promedio & 88,0 & 90,2 & 89,4 & 90,4 & 92,8 & 90,0 \\
\hline
\end{tabular}

Fuente: Figueiredo y Limongi (1999), a excepción de los datos relativos a FHC II y Lula (Banco de datos Necon).

prácticamente en su totalidad en el Ejecutivo y aprobada casi en su mayoría en régimen de urgencia.

Por otra parte, podemos analizar los datos en sí mismos. Para el período 19862004 el promedio de disciplina quedó en torno a 90\%. Considerando apenas el período más reciente, observamos que en ambos mandatos de FHC el patrón de disciplina de los partidos es bastante similar, a excepción del PP, antiguamente PPB, que aumentó su nivel de adhesión en el segundo mandato de FHC. Durante los dos primeros años del gobierno de Lula, la caída del promedio de disciplina fue causada por el aumento de la indisciplina en el PPB y en el PDT y, en mayor grado, en los dos socios principales de la ex-coalición en el gobierno FHC, ahora en la oposición. En otras palabras, existen evidencias de que la presencia en el gobierno de los partidos de izquierda puede producir caídas en los indicadores de disciplina en los partidos de derecha; al contrario, sería la no participación formal en el gobierno el factor que causaría un impacto negativo sobre la disciplina. Con todo, aún es temprano para afirmar aquello con seguridad.

35 En la selección de votaciones, opté por el método sugerido por Figueiredo y Limongi (1999), el cual considera que evidencian algún grado de conflicto las votaciones donde, al menos un partido de los siete mayores, expresa una posición contraria a los otros, y cuando ocurre la oposición de, al menos, un 10\% en el plenario. No obstante, algunas adaptaciones se hicieron necesarias a fin de incluir otros partidos menores. 
Las dos vertientes ofrecen elementos importantes al debate acerca del carácter e intensidad de la disciplina partidaria. Por un lado, los índices de disciplina calculados con respecto a las votaciones nominales pueden representar la última fase de un proceso intenso de negociación, como lo señala Ames (2001). Este no es un hecho irrelevante, pues los índices pueden no revelar los costos de transacción incurridos. Sin embargo, por el otro, es fundamental considerar que los índices del período post-Constitución de 1988 son consistentemente más elevados que en el período democrático anterior (que también era un régimen presidencialista, federal y con representación proporcional de lista abierta). Vale decir que el argumento de Ames no ayuda a entender la variación entre los períodos. Si tomamos en cuenta principalmente los trabajos de Figueiredo y Limongi (1999) y Santos (2003a), la explicación residiría en la centralización del proceso decisorio en la presidencia y en los liderazgos partidarios.

Por consiguiente, se puede señalar que, a partir de la Constitución de 1988, la dinámica legislativa adquirió un fuerte contenido partidario, elemento que se agregó a la tradición de montaje de coaliciones a favor y en contra del Ejecutivo con base en la capacidad distributiva de los parlamentarios.

\section{Conclusión}

Hemos visto entonces que el Congreso brasileño es una institución reactiva que mezcla componentes distributivos y partidarios en su organización y en su proceso decisorio. Se abre una línea de reflexión interesante cuando imaginamos en qué forma sería posible ampliar la capacidad pro-activa e informativa del Legislativo.

La experiencia de gobiernos minoritarios en Europa y en EE.UU., en que la gobernabilidad es garantizada a través del montaje de coaliciones tópicas, negociadas caso por caso, es de gran relevancia como punto de partida para la reflexión. En este tipo de gobierno, con frecuencia, un paquete de proyectos es negociado ex ante, apoyado por sectores de la sociedad y liderazgos partidarios nacionales y sociales. Este paquete debe justamente su viabilidad al hecho de haber sido legitimado en ambientes externos al Congreso. La negociación también puede acontecer al interior de la propia instancia representativa, oportunidad en la cual el carácter minoritario asume rasgos más nítidos. En este contexto, se deberán valorizar organismos suprapartidarios del Legislativo, tales como las comisiones técnicas, ya que la participación institucionalizada de miembros de la oposición en el diseño de los proyectos es de importancia fundamental. Conforme a lo anteriormente mencionado, el desafío en este contexto sería el de fortalecer el Congreso brasileño como actor pro-activo, proponente, dotado de visión propia sobre los rumbos de la agenda gubernamental. La pregunta sería entonces la siguiente: ¿sería la orientación programática capaz de vencer la orientación patrimonialista, presente en buena parte de la vida de nuestras agremiaciones?

La lección primera y fundamental extraída de las secciones empíricas radica en que los beneficios de formar parte del gobierno en Brasil son muy elevados. Y 
en segundo lugar, los costos de negociar con los grandes partidos en torno a una agenda de policies son también bastante altos. Tratemos separadamente cada una de estas lecciones.

El poder de nombrar y dimitir, el poder de retener y liberar recursos presupuestarios, además del enorme poder de definición del contenido y timing de la agenda de decisiones gubernamentales, son los principales instrumentos de atracción de los partidos y representantes al seno de la coalición gubernamental en el Legislativo brasileño. Para un partido cualquiera surgen dos alternativas de manera muy clara: la primera consiste en correr el riesgo de participar de un gobierno que eventualmente puede fracasar y, por lo tanto, asumir los costos políticos de tener alguna responsabilidad en el proceso; y la segunda es la de decidir permanecer fuera de la coalición, asumiendo el papel de opositor, que puede ser de naturaleza constructiva o sistemática. La adopción de uno u otro tipo dependerá de variables como la popularidad del Presidente, el tamaño y la cohesión de la base parlamentaria del gobierno, la capacidad de comunicación a los electores, etc. El hecho es que, en las actuales condiciones de la política brasileña, la atracción ejercida por el poder ejecutivo es considerable.

Para un gobierno que precisa negociar una agenda con los partidos de oposición, los costos de transacción son elevados, porque éstos se ven totalmente desprovistos de medios a fin de implementar políticas de gobierno. Como cualquier liberación de recursos presupuestarios exige una decisión del Ejecutivo, y como hacer políticas públicas significa liberar recursos, entonces toda y cualquier política pública en el país sólo puede ser hecha por el gobierno. Los partidos de oposición no perciben ganancia alguna en cooperar con un Presidente que irá a "facturar" de manera casi monopolizadora los beneficios de ejecución de programas gubernamentales. De ahí la imposibilidad virtual de contar con la cooperación de partidos oposicionistas y, por consiguiente, de gobernar con minoría en el parlamento.

Es esta alienación de los partidos parlamentarios respecto de los programas de asignación de recursos presupuestarios la que hace esencial para el gobierno montar coaliciones mayoritarias, eventualmente súper mayoritarias, dependiendo de la naturaleza de la agenda y de la disciplina que se espera de sus socios originales. En otros términos, para el Presidente de Brasil, gobernar con una minoría, o aún con mayorías mínimas, es algo muy costoso pues, desde el punto de vista de los partidos de oposición, no hay incentivos para cooperar; por otra parte, participar del gobierno es altamente benéfico, ya que fuera del mismo no hay cómo asignar recursos. Con todo, al optar por la incorporación de los partidos originalmente de oposición a la coalición de gobierno, este último interfiere en la comunicación que esos partidos tratan de establecer con los electores -he ahí uno de los desafíos institucionales de nuestro sistema político-. En suma, una reforma del poder legislativo, con miras a una vida partidaria más estable, además de una distribución más equilibrada del poder en nuestro sistema político, debe atacar los dos puntos siguientes: a) elevar los costos políticos de formar parte del gobierno; b) aumentar los beneficios de mantenerse en la oposición. 


\section{Bibliografía}

Abranches, Sérgio H. De. 1988. "Presidencialismo de Coalizão: O Dilema Institucional Brasileiro". Dados 31 (1): 5-38.

Ames, BArry. 2001. The Deadlock of Democracy in Brazil. Ann Arbor: University of Michigan Press.

Amorim Neto, Octavio. 2000. "Gabinetes Presidenciais, Ciclos Eleitorais e Disciplina Legislativa no Brasil". Dados 43 (3): 479-519.

. 2004. "O Poder Executivo, Centro de Gravidade do Sistema Político Brasileiro". En Lúcia Avelar y Antônio Cintra, Sistema Político Brasileiro: Uma Introdução. São Paulo: Fundação Konrad-Adenauer/Fundação Unesp Ed., 123-133.

Cox, Gary; Mc Cubbins, Mathew. 2003. "Agenda Power in Brazil's Câmara dos Deputados, 1989-98". World Politics 55 (4): 550-578.

Amorim Neto, Octavio; Santos, Fabiano. 2002. "A Produção Legislativa do Congresso: Entre a Paróquia e a Nação". En Vianna, Luiz Werneck. 2003, A Democracia e os Três Poderes no Brasil. Belo Horizonte: Editora UFMG, Río de Janeiro: IUPERJ/FAPERJ. 2001. "The Executive Connection: Patronage and Party Discipline in Brazil". Party Politics, 7, (2): 213-234.

2003. "O Segredo Ineficiente Revisto: O que Propõem e o que Aprovam os Deputados Brasileiros". Dados 46 (4): 661-697.

Anastasia, Fátima; Melo, Carlos Ranulfo F. de; Santos, Fabiano. 2004. Governabilidade e Representação Política na América do Sul. São Paulo: Editora da UNESP/Fundação Konrad Adenauer.

Blondel, JeAn. 1973. Comparing Legislatures. Englewood-Cliffs, NJ: Prentice Hall.

Brady, David W.; Volden, Craig. 1998. Revolving Gridlock: Politics and Policy from Carter to Clinton. Colorado: Westview Press.

Cain, Bruce; Ferejohn John; Fiorina, Morris. 1987. The Personal Vote: Constituency Service and Electoral Independence. Harvard: Harvard University Press.

Carvalho, Nelson Rojas. 2003. E no Início Eram as Bases: Geografia Política do Voto e Comportamento Legislativo no Brasil. Río de Janeiro: Revan.

Cheibub, José Antonio. 2005. Why Are Presidential Democracies so Fragile? New Haven. Manuscrito.

Cox, Gary; Mc Cubbins, Mathew. 1993. Legislative Leviathan: Party Government in the House. Berkeley: University of California Press.

Ferejohn, JoHn. 1974. Pork Barrel Politics: Rivers and Harbors Legislation 1947-1968. Stanford: Stanford University Press.

Figueiredo, Argelina C. 2000. "Government Performance in Multiparty Presidential Systems: The Experiences of Brazil". Trabajo presentado en XVIII World Congress of Political Science, International Political Science Association, ciudad de Québec, agosto. e Limongi, Fernando G. P. 1999. Executivo e Legislativo na Nova Ordem Constitucional. Río de Janeiro: Fundação Getulio Vargas Editora.

2002. "Incentivos Eleitorais, Partidos e Política Orçamentária". Dados 45 (2): 303344.

FIORINA, Morris P. 1977. Congress: Keystone of the Washington Establishment. New Haven: Yale University Press.

Gilligan, Thomas; Krehbiel, Keith. 1987. "Collective Decision-Making and Standing Committees: An Informal Rationale for Restrictive Amendment Procedures". Journal of Law, Economics, and Organization 3: 287-335.

Kiewiet, D. Roderick; Mc cubbins, Mathew D. 1991. The Logic of Delegation: Congressional Parties and the Appropriations Process. Chicago: The University of Chicago Press. 
Krehbiel, KeITH. 1990. Information and Legislative Organization. Ann Arbor: The University of Michigan Press.

Lima Junior, Olavo Brasil de. 1993. Democracia e Instituições Políticas no Brasil dos Anos 80. São Paulo: Edições Loyola.

Lowenberg, Gerhard; Patterson, Samuel. 1979. Comparing Legislatures. Boston: Little Brown.

Mayhew, David R. 1974. Congress: The Electoral Connection. New Haven: Yale University Press.

Melo, Carlos Ranulfo Félix De. 2000. "Partidos e Migração Partidária na Câmara dos Deputados". Dados 43 (2): 302-240.

Meneguello, Rachel. 1998. Partidos e Governos no Brasil Contemporâneo (1985-1997). São Paulo: Paz e Terra.

Mezey, Michael L. 1985. "Functions of Legislatures in the Third World". En G. Lowenberg, S. Patterson y M. E. Jewell (eds.), Handbook of Legislative Research. Cambridge, MA: Harvard University Press.

Nicolau, Jairo M. 1996. Multipartidarismo e Democracia. Río de Janeiro: Fundação Getulio Vargas Editora.

Pacheco, Luciana B.; Mendes, Paula R. 1998. Questões sobre o Processo Legislativo e Regimento Interno. Centro de Documentação e Informação, Câmara dos Deputados.

Packenham, Robert. 1970. "Legislatures and Political Development". En A. Kornberg y L. D. Musolf (eds.), Legislatures in Developmental Perspectives. Durham, NC: Duke University Press.

Pessanha, Charles. 1997. Relações entre os Poderes Executivo e Legislativo no Brasil: 19461994. Tesis de Doctorado, USP, São Paulo.

Pereira, Carlos; Mueller, Bernardo. 2000. "Uma Teoria da Preponderância do Poder Executivo: O Sistema de Comissões no Legislativo Brasileiro". Revista Brasileira de Ciências Sociais 15 (43): 45-68.

; Rennó, Lúcio. 2001. "O que é que o Reeleito tem? Dinâmicas Político-Institucionais Locais e Nacionais nas Eleições de 1998 para a Câmara dos Deputados”. Dados 44 (2): 133-172.

Polsby, Nelson. 1968. "The Institutionalization of the U. S. House of Representatives". American Political Science Review 62: 144-168.

Power, Timothy J. 1998. "The Pen is Mightier than the Congress: Presidential Decree Power in Brazil". En Carey \& Shugart (orgs.), Executive Decree Authority. New York: Cambridge University Press.

Rohde, David W. 1991. Parties and Leaders in the Postreform House. Chicago: The University Press.

Samuels, David J. 2003. Ambition, Federalism, and Legislative Politics in Brazil. Cambridge: Cambridge University Press.

Santos, Fabiano. 1997. "Patronagem e Poder de Agenda na Política Brasileira". Dados 40 (3): 465-491.

2000. "Escolhas Institucionais e Transição por Transação: Sistemas Políticos de Brasil e Espanha em Perspectiva Comparada". Dados 43 (4): 637-670.

2003a. "Em Defesa do Presidencialismo de Coalizão". En Herman, Klaus y Moraes, Filomeno. Reforma Política no Brasil: Realizações e Perspectivas. Fortaleza: Fundação Konrad Adenauer.

2003b. O poder legislativo no Presidencialismo de Coalizão. Belo Horizonte: Editora UFMG.

SinClAIR, BARBARA. 1995. Legislators, Leaders and Lawmaking: The U.S. House of Representatives in the Postreform Era. Baltimore: The Johns Hopkins University Press. 
Shepsle, Kenneth A. 1979. The Giant Jigsaw Puzzle. Chicago: The University of Chicago Press.

Strom, KaAren. 1990. Minority Government and Majority Rule. Cambridge: Cambridge University Press.

Weingast, Barry; Marshall, William. 1983. "The Industrial Organization of Congress; or, Why Legislatures, Like Firms Are Not Organized as Markets?". Journal of Political Economy 96: 132-163. 
